\title{
Accurate diagnosis and self-care support for women with lipoedema
}

\author{
Lipoedema is a little-known but relatively common condition that can be challenging to \\ diagnose. Anne Williams and Isobel MacEwan provide practice nurses with the knowledge to \\ give practical and emotional support to affected patients
}

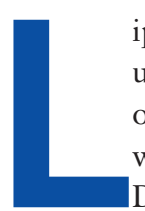

ipoedema is a long-term, progressive condition, usually presenting as symmetrical enlargement of the legs and buttocks, and mainly affecting women (Langendoen et al, 2009; Fife et al, 2010).

Distinct from obesity or lymphoedema, lipoedema is associated with an unusual distribution and proliferation of diet-resistant inflammatory fat tissue (Figures 1 and 2) and symptoms such as pain (Fife et al, 2010). Lipoedema may also affect the upper body and arms and can lead to secondary lymphoedema, sometimes referred to as lipo-lymphoedema. This article provides background to lipoedema, describes how lipoedema affects women, and how it is diagnosed. It identifies key points for primary care practitioners providing self-care support for women with lipoedema, and describes the work of Talk Lipoedema, a third sector support organisation in the UK (Box 1).

\section{Background}

Lipoedema often first develops around puberty and appears to be exacerbated by hormonal change during pregnancy and the menopause (Fife et al, 2010). It has been estimated that lipoedema may affect up to $11 \%$ of women after puberty (Földi and Földi, 2003), although accurate epidemiological evidence is lacking. Forner-Cordero et al (2012) reported $19 \%$ of patients attending their lymphoedema clinic in Spain to have lipoedema. A specific cause of lipoedema has not been identified, but positive family history may be present in up to $64 \%$ of cases (Langendoen et al, 2009), with possible autosomal dominance inheritance. Hormonal, connective tissue and autoimmune factors may also be involved (Langendoen et al, 2009; Szél et al, 2014). Anecdotal evidence indicates that lipoedema may be associated with connective tissue disorders such as Ehlers-Danlos syndrome, or conditions such as hypermobility or fibromyalgia (Talk

Dr Anne Williams, lecturer in nursing/lymphoedema nurse consultant, Queen Margaret University,

Edinburgh; trustee, Talk Lipoedema

Isobel MacEwan, chair, Talk Lipoedema

Submitted for publication 20 May 2016; accepted for publication following peer review 8 June 2016

\begin{abstract}
Lipoedema is a long-term, progressive condition, usually presenting as symmetrical enlargement of the legs and buttocks, and mainly affecting women. Distinct from obesity or lymphoedema, lipoedema is associated with an unusual distribution and proliferation of diet-resistant inflammatory fat tissue. This article provides background to lipoedema diagnosis and discusses self-care support for women with lipoedema.
\end{abstract}

Key words | Lipoedema | Secondary lymphoedema | Compression therapy | Self care

Lipoedema, 2015) (Figure 3). Early diagnosis of lipoedema is essential, so women can learn self-management approaches that minimise progression of symptoms and reduce the risk of complications such as lymphoedema and cellulitis (British Lymphology Society, 2015).

\section{Pathophysiology of lipoedema}

The exact pathophysiology of lipoedema is unclear (Szél et al, 2014) but various processes appear to contribute to the characteristic changes of lipoedema (Table 1). Fat cells increase in number, becoming inflamed and infiltrated by macrophages. Blood capillaries become dilated, fragile and leaky, leading to excess capillary filtration and further inflammation (Fife et al, 2010; Szél et al, 2014). As fat tissues enlarge they are less well perfused and become cold to touch. Lymphatics may be normal in the early stages, but lymphatic microaneurysms develop in the later stages (Amann-Vesti et al, 2001). Lymph drainage becomes compromised and protein-rich oedema accumulates in the tissues, leading to secondary lymphoedema. Magnetic resonance imaging (MRI) has shown enlarged lymphatic vessels and dermal backflow in people with lipo-lymphoedema (Lohrmann et al, 2009). These pathophysiological changes provide strong indication for the use of compression therapy in this group of patients (Table 2).

\section{Diagnosis of lipoedema}

Diagnosis is currently undertaken by medical and family history, clinical examination, and identification of 


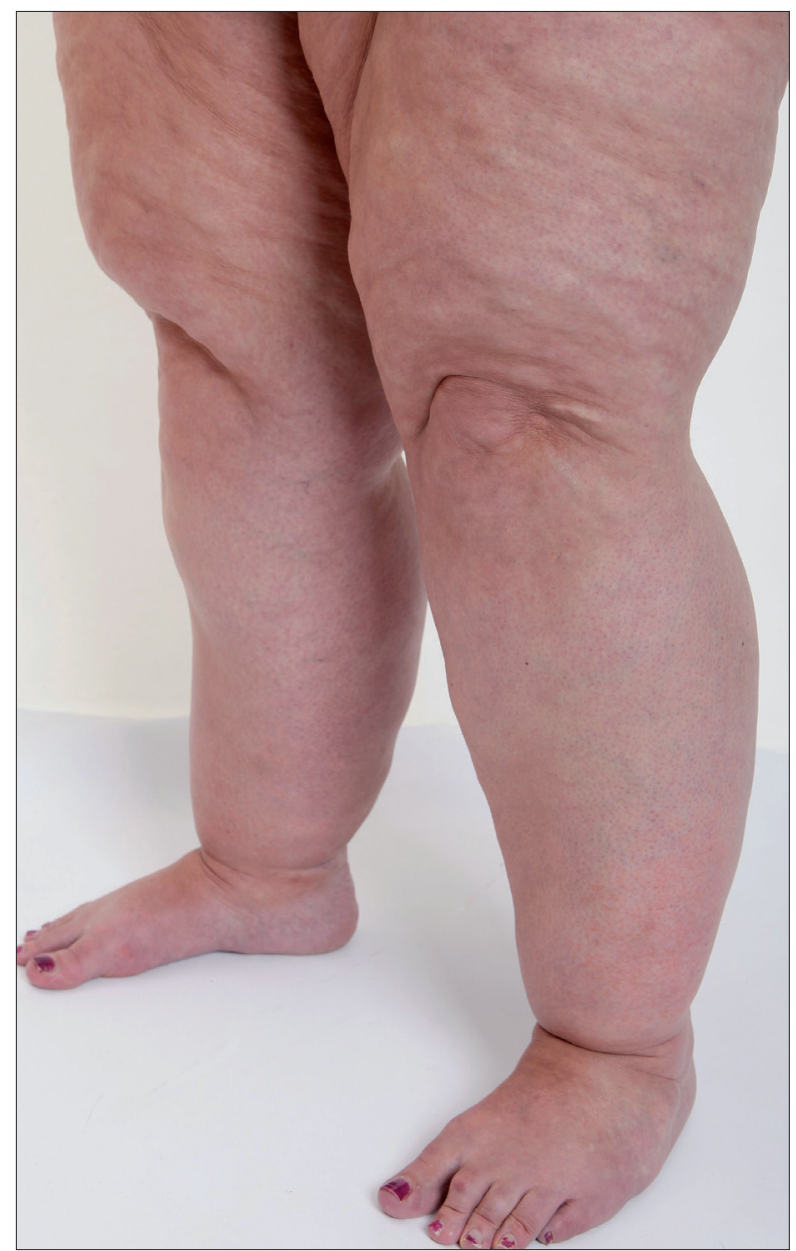

Figure 1. A woman with early stage lipoedema

characteristic signs and symptoms (Table 1), sometimes within a specialist lymphology or dermatology centre. In the early stages the skin is soft and loose, with characteristic changes in leg shape, an ankle 'bracelet', and fat pads at the knees (Figures 1 and 2). The feet are usually not affected in the early stages, in contrast to someone with lymphoedema. Affected tissues may be tender when pressed, bruise easily, and may feel cold to the touch. Fat nodules or small pea-sized lipomas may be palpated under the skin (Herbst, 2012) and larger nodules or lipomas may later develop. As the condition progresses, fat lobes bulge at the thighs and knees, the tissues become fibrosed with deep skin folds (Figure 2), and there is a risk of skin damage and cellulitis.

Making a diagnosis of lipoedema can be challenging (Fetzer and Wise, 2015). The Lipoedema UK Big Survey of 240 women with lipoedema reported 44 years as the average age of diagnosis (Fetzer and Fetzer, 2015), often when the woman's health had deteriorated and lipoedema was at a late stage. Lipoedema must be differentiated from, but may exist alongside, conditions such as lymphoedema, obesity, chronic venous insufficiency, or oedema due to heart, kidney or liver failure. In contrast to lipoedema, obesity affects the whole body, responds to weight loss, is not painful, and is not usually associated with

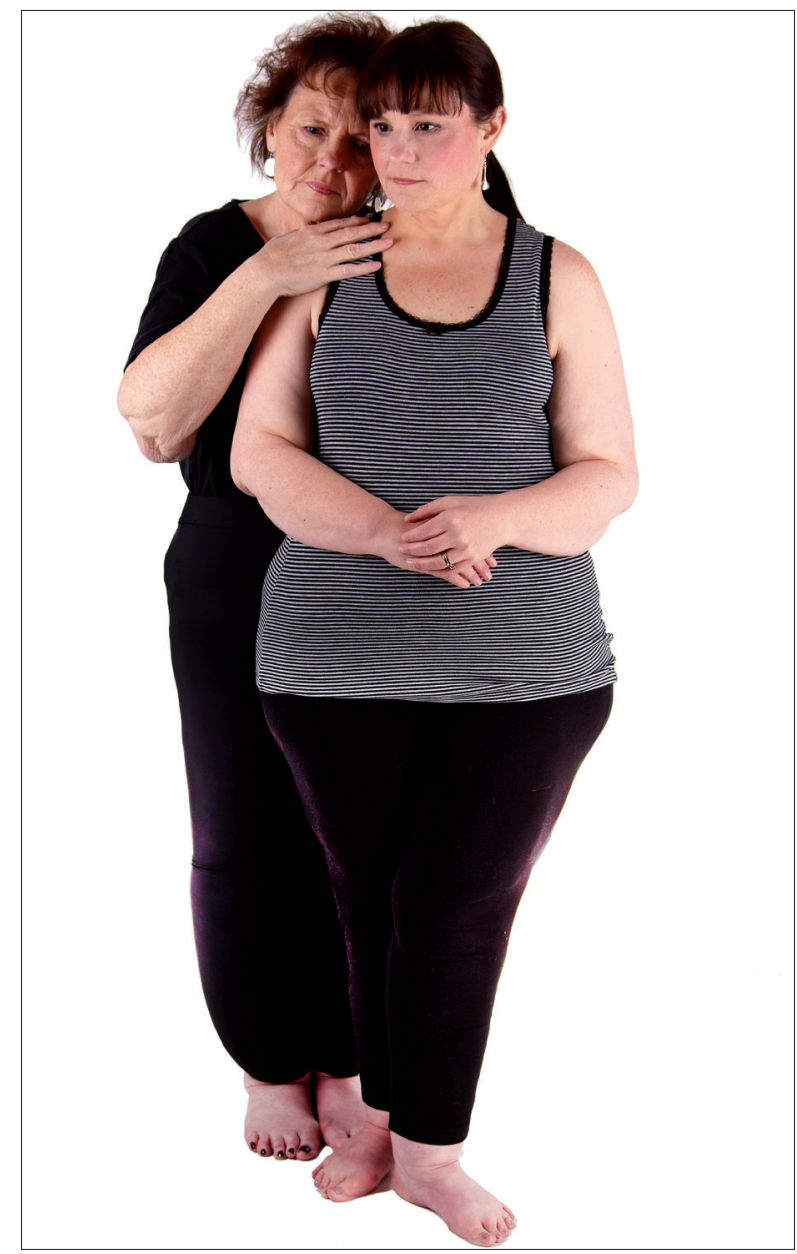

Figure 2. A mother and daughter with lipoedema, showing a typical 'lipoedema shape'

bruising. Measures such as weight and body mass index do not appear to be useful parameters for diagnosing or monitoring changes in someone with lipoedema (Langendoen et al, 2009).

Diagnostic tests such as lymphoscintigraphy, MRI, computerised tomography (CT), and ultrasonography are not routinely used outside specialist centres, and are most useful to exclude other pathologies. More recently, small studies have described muscle testing (Smeenge et al, 2014), and tissue dielectric testing (Birkballe et al, 2014) as ways of differentiating lipoedema, but further research is required. Blood tests such as C-reactive protein may be useful in identifying infections such as cellulitis (British Lymphology Society, 2015), and hormonal testing may be required to investigate thyroid and pituitary function (Herbst, 2012). Rare types of adipose tissue disorders such as Dercum's or Madelung's disease (Herbst, 2012) should also be excluded. More work is required to develop clinically relevant markers and diagnostic criteria for lipoedema.

\section{Experiences of women living with lipoedema}

Lipoedema is frequently misdiagnosed as obesity or $\stackrel{N}{0}$ 


\section{Box 1. About Talk Lipoedema}

Talk Lipoedema is a UK-based third sector organisation that is active across the UK. It provides support to people with lipoedema, their families and carers. Talk Lipoedema initiates and participates in various projects to increase awareness of the disease and improve research evidence. It has a vision for the future that everyone who has lipoedema will be given an accurate and timely diagnosis, receive an individual care plan and have access to an appropriate range of services and support with self-management. Talk Lipoedema believes that education is the key to empowering people with lipoedema, and improving treatments and care. Talk Lipoedema offers 24/7 support through a number of moderated social media platforms including: a web-based forum on the website, Twitter, and closed groups on Facebook where women can talk privately and support each other. Talk Lipoedema also run a series of roadshows throughout the UK for women with lipoedema and their families, along with regular conferences for professionals and people living with the condition.

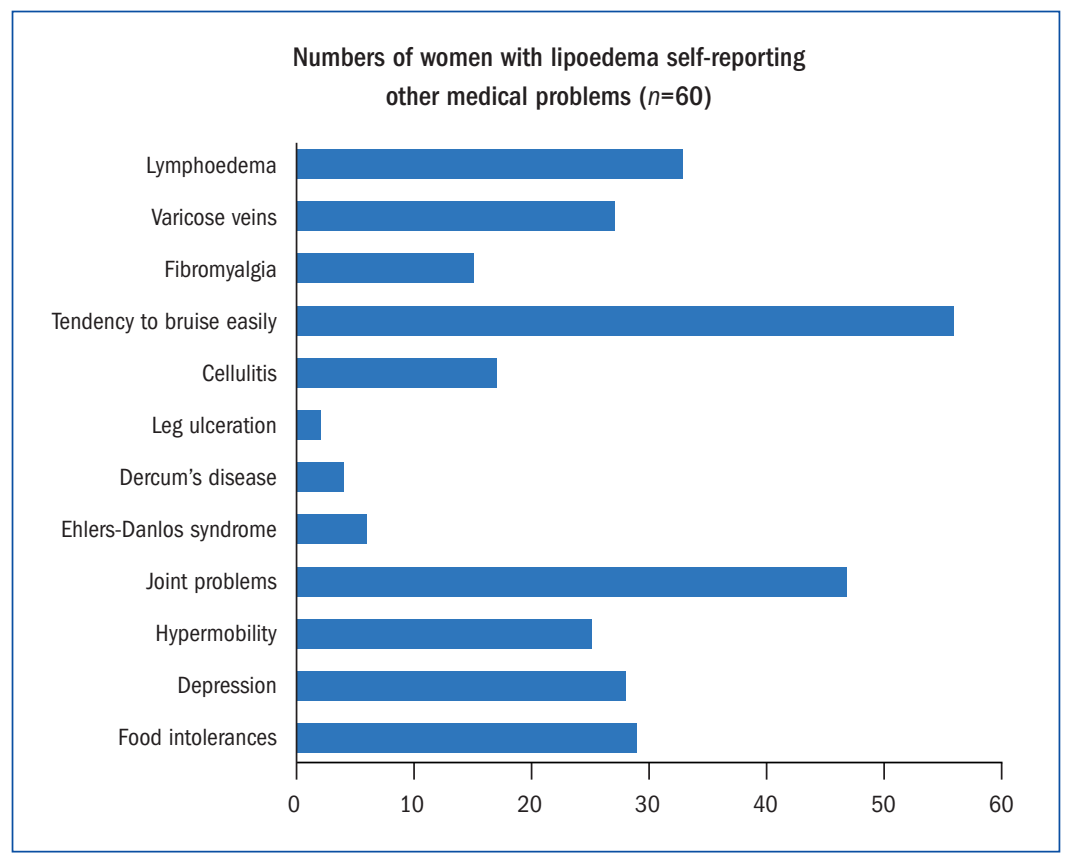

Figure 3. Experience of medical conditions reported by women with lipoedema (Talk Lipoedema, 2015). Sixty women completed the questionnaire; their median age was 48 years (range $22-74$ years)

\section{Table 1. A summary of the characteristic signs of lipoedema}

Bilateral symmetrical enlargement of the legs that may also affect the buttocks, abdomen and arms, but may lead to disproportionate body shape

Fat 'bracelet' at the ankle, and fat pads at the knees

Feet are usually not affected in the early stages

Skin feels soft, loose, cold, and may be dimpled

Tenderness, pain in the tissues, particularly on pressure

Small fat nodules may be palpated in the subcutaneous tissues

Tendency to bruising and venous varicosities may be evident

Lipoedema fat is unresponsive to weight loss

Reduced mobility and changes in gait due to fat distribution lymphoedema. Consequently, a woman may live for many years with the physical and emotional challenges of lipoedema (Table 3) before receiving a correct diagnosis (Evans, 2013). Attempts to lose weight usually lead to a reduction in fat at non-lipoedema areas of the body, with little effect on the lipoedema fat (Fife et al, 2010). Women with lipoedema often talk of having a complex relationship with food, and there is some evidence suggesting they may be at particular risk of mental health problems such as depression (Herbst, 2012; Fetzer and Wise, 2015; Talk Lipoedema, 2015). A summary of key issues experienced by women who are members of Talk Lipoedema highlights various physical and functional problems (Table 3). Issues such as gait change may be significant due to leg heaviness, and fat lobes at the insides of knees and thighs may alter walking patterns (Dutch Foundation Network for Lympedema and Lipedema, 2014). However, research evidence relating to the physical and the psychosocial implications of lipoedema, and quality of life in this group of women, is very limited.

\section{Support with self-management of lipoedema}

When finally diagnosed with lipoedema a woman may feel a mix of relief and distress to learn that her various symptoms, experienced over many years, represent a lifelong condition and should be taken seriously (Fetzer and Fetzer, 2015). Management of lipoedema requires a partnership approach between women and health professionals, supporting and empowering women towards effective self-management and lifestyle changes that will alleviate symptoms and prevent progression of the condition (Dutch Foundation Network for Lympedema and Lipedema, 2014; Fetzer and Fetzer, 2015).

A small number of women may be suitable for liposuction, although this is not a curative treatment, and research evidence is limited (Rapprich et al, 2011; Schmeller et al, 2012; Baumgartner et al, 2015). Conservative therapy approaches and self-care are key to long-term management of lipoedema (Szolnoky and Kemény, 2010; Fetzer and Wise, 2015) and include: healthy eating habits; skin care and protection to prevent damage and cellulitis; compression therapy; manual lymphatic drainage, exercise, movement and various other techniques to improve lymph drainage and skin/tissue condition.

\section{Healthy eating habits}

Although lipoedema fat does not generally respond to dietary measures, healthy eating habits, weight management and reduction of normal fat are encouraged in women with lipoedema, particularly prior to any surgery. However, conventional advice, such as the Eatwell Guide, may not be appropriate for women with lipoedema. Nutrition and dietary changes such reducing intake of foods that produce inflammation in the body (sugar, carbohydrates, red meat) are recommended by some lipoedema medical specialists (Herbst, 2012), and further research is required. 
Table 2. Compression therapy choices for women with lipoedema

Compression garment

- Choice of styles-below knee, thigh length, panty type; mainly in beige or black

- Compression class 1 may be most suitable for (tender) lipoedema

- Compression class 2 or 3 may be required if lymphoedema component evident

- Custom-made, flat knit garments may ensure accurate fitting and accommodate poor shape better than circular knit garments

- Circular knit elastic garments may be unsuitable for women with lipoedema due to skin folds and soft tissue

- Some women do not require foot compression; a legging-type garment can be prescribed

- An applicator may be required to aid donning and doffing (Wounds UK, 2015)

\section{Compression bandaging}

- Multi-component inelastic systems may be used to reduce oedema, improve limb shape and tissue condition, and heal ulceration

- May be reapplied daily, particularly if oedema is reducing, and used in conjunction with other therapies including manual lymph drainage, skin care and exercise

Compression-wrap with velcro attachments

- Adjustable compression device consisting of inelastic material sections that wrap around the leg and are secured

- Used to reduce oedema and improve skin integrity

- Designed to allow the person or the carer to apply and reapply in the home setting

- May be used as an essential part of post-operative care following liposuction surgery

\section{Skin care and protection}

Skin care and protection includes daily washing of the skin, use of appropriate emollients, avoidance of allergens and prevention or treatment of skin damage such as scratches, fungal infection, blisters, burns, insect bites or blunt force. Where possible, it is important to avoid taking blood pressure on a lipoedematous limb, taking a blood sample, or giving an injection into lipoedematous fat, as this can be excruciatingly painful for the woman (Table 3), and may lead to significant bruising.

Skin folds in particular can become red and infected, and some women may find personal care awkward if their mobility is affected. Antiseptic, antifungal or other skin and wound care products may be required and women may need advice on clothing and footwear that can be worn comfortably to disguise the swelling, improve gait and prevent falls.

\section{Compression therapy}

Compression therapy is essential for successful management of lipoedema symptoms, as compression counteracts excess capillary filtration, supporting venous and lymphatic function, and reducing oedema accumulation and inflammatory processes in the interstitial tissues (Partsch and Moffatt, 2012; Wounds UK, 2015). A wide range of compression products is available (Table 2), and specific skills and knowledge are required to prescribe correctly to ensure garments fit well and do not cause skin damage or pain. A course of compression bandaging may be required for someone who has secondary lymphoedema, or chronic ulceration.
Women with lipoedema may not be suitable for highly elastic circular lymphoedema garments due to their soft skin, deep skin folds, and fat lobes. Compression garments without feet sections may also be appropriate for some women if their feet are not swollen. A choice of garments may be required for different activities, and once prescribed women should be followed up to evaluate suitability and fit. Women may need advice on how to apply and remove compression products, and to be prescribed a garment applicator if necessary (Wounds UK, 2015). Individualised, holistic assessment and a partnership approach are essential, as compression requirements vary between individuals. Finding products that are acceptable to a woman and effective is critical to a good long-term outcome for the woman and to ensure cost-efficiency of care.

\section{Manual lymphatic drainage}

Manual lymphatic drainage (MLD) is a gentle but very specific type of massage designed to enhance lymph drainage, remove excess fluid from the tissues, reduce inflammation, and alleviate symptoms such as pain (Wittlinger et al, 2011). This is available through some NHS lymphoedema clinics, but women may access MLD privately through organisations such as MLD UK. Currently, there is no empirical evidence to inform the use of MLD in women with lipoedema but women often find MLD helpful in managing symptoms such as pain and swelling. Self-lymph drainage techniques such as gentle self-massage or skin brushing are undertaken by some women. Caution is required with skin brushing, as this 
Table 3. Physical and emotional challenges reported by women from Talk Lipoedema

- Appearance of my legs causes distress; I dislike my swollen legs, and the loss of shape at my knees

- Severe pain when having my blood pressure taken on the lipoedema arm

- Heaviness and poor mobility leading to a risk of falling

- Being unable to play with my children

- I find it difficult being judged by others and experiencing unkind comments that I am overweight or my legs are swollen

- Poor recognition of lipoedema and lack of empathy from health professionals

- General lack of knowledge about lipoedema within the public

- Difficulties finding clothes and footwear that fit; having to plan every outfit around the size and shape of their legs and arms; not being able to wear nice summer clothing

- People assuming I eat too much

- Anxiety about passing the condition on to my children

- Being told to diet, and not being believed when telling others that I eat healthily

- Fear of the future and how the condition will progress

- Constant pain in my enlarged limbs

- Having to give up activities such as driving, working and certain sports

- Having to struggle with putting on compression stockings every morning, and wearing them in the heat

- Constant tiredness, making it difficult for me to care for my children

- Having recurrent cellulitis

- Feeling a complete lack of control over the lipoedema

- Fearing the condition will progress

\section{Table 4. Advice for health professionals from women at}

\section{Talk Lipoedema}

- Listen to us, care for and encourage us

- Believe that we are exercising and eating healthy food when we say we are

- Recognise that lipoedema swelling does not to respond to diuretics as they do not improve lymph drainage

- Believe us when we say we are in constant pain

- Respect that women know their bodies

- Take care when taking blood pressure as it can be excruciatingly painful on the arm; look for alternatives such as taking it on the lower arm or leg

- Find out more about lipoedema and how it can be managed

A lipoedema online learning course is available from the Royal College of General Practitioners: www.rcgp.org.uk/learning/online-learning/ole/ lipoedema-an-adipose-tissue-disorder.aspx

Find further information from:

- Talk Lipoedema at: www.talklipoedema.org

- Lipoedema UK at: www.lipoedema.co.uk

- Manual lymphatic drainage UK at: www.mlduk.org.uk can traumatise the skin, and increase capillary filtration, unless an extremely soft brush is used.

\section{Movement and exercise}

A personalised approach to exercising is important as individual ability and capacity vary significantly. Movement is essential for healthy venous and lymph drainage, but excessive exercise can promote capillary filtration and cause joint pain. The range of approaches suitable for women with lipoedema include: seated exercise, swimming, Nordic walking, Tripudio, Pilates, and yoga. High impact sport, such as long-distance running, may be unsuitable, particularly in someone with gait changes or joint problems.

\section{Conclusion}

Lipoedema appears to be a relatively common condition, although research evidence is required to inform practice and better understand the disease and its impact on women and their families. Practice nurses have a key role in supporting women with lipoedema to achieve an accurate diagnosis, and signposting them to appropriate services such as lymphoedema practitioners, specialist lymphology centres, manual lymphatic drainage therapists and support organisations such as Talk Lipoedema. Effective support may take many forms, and women from Talk Lipoedema have collated a short summary of advice on what types of support they would like from health professionals (Table 4).

There is good evidence that women with lipoedema experience many physical, psychosocial and emotional challenges that have a significant influence on their quality of life. Early diagnosis and support is essential to preventing progression of the disease. Practice nurses can provide practical and emotional support with self-management to women with lipoedema, and a person-centred care plan, enabling women to better understand their condition, and effectively manage it over the long term. PN

\section{Amann-Vesti BR, Franzeck UK, Bollinger A (2001) \\ Microlymphatic aneurysms in patients with}

lipedema. Lymphology 34(4): 170-5

Baumgartner A, Hueppe M, Schmeller W (2015) Longterm benefit of liposuction in patients with lipoedema. A follow up study after an average of 4 and 8 years. British Journal of Dermatology 17: doi: 10.1111/bjd.14289

Birkballe S, Jensen MR, Noerregaard S, Gottrup F, Karlsmark T (2014) Can tissue dielectric constant measurement aid in differentiating lymphoedema from lipoedema in women with swollen legs? British Journal of Dermatology 170(1): 96-102. doi: 10.1111/bjd.12589

British Lymphology Society (2015) Consensus document on the management of cellulitis in lymphoedema. British Lymphology Society and Lymphoedema Support Network www.thebls.com/the-bls/professional-and-patients/cellulitisin-lymphoedema/ (accessed 10 June 2016)

Dutch Foundation Network for Lymphedema and Lipedema (2014) Lipoedema Guidelines in the Netherlands, Dutch Society for Dermatology and Venereology (NVDV) Uretcht. http://tinyurl.com/jcqgjlz (accessed 6 June 2016)

Evans S (2013) Lipoedema. The first UK patient survey. $\mathrm{Br}$ 


\section{KEY POINTS}

- Lipoedema is a chronic inflammatory condition affecting the adipose tissue and should be differentiated from obesity

- Primary care practitioners have a role in ensuring accurate diagnosis, and appropriate self-care support for women with lipoedema

- Well-fitting compression therapy is key to the successful management of lipoedema
A review of the literature. Br J Dermatol 161: 980-6. doi: 10.1111/j.1365-2133.2009.09413.x

Lohrmann C, Foeldi E, Langer M (2009) MRI imaging of the lymphatic system in patients with lipedema and lipolymphedema. Microvasc Res 77: 335-9

Partsch H, Moffatt C (2012) An overview of the science behind compression bandaging for lymphoedema and chronic oedema. In: Compression Therapy: A Position Document on Compression Bandaging. International Lymphoedema Framework in Association with the World Alliance for Wound and Lymphoedema Care, pp12-22

Rapprich S, Dingler A, Podda M (2011) Liposuction is an effective treatment for lipedema-results of a study with 25 patients. J Dtsch Dermatol Ges 9(1): 33-40

J Community Nurs 18(4 suppl): S26-27. doi: 10.12968/ bjcn.2013.18.Sup4.S26

Fetzer A, Fetzer S (2015) Early lipoedema diagnosis and the RCGP e-learning course. Br J Community Nurs 20(4 suppl): S22-28. doi: 10.12968/bjen.2015.20.Sup4.S22

Fetzer A, Wise C (2015) Living with lipoedema. Reviewing different self-management techniques. $\mathrm{Br}$ J Community Nurs 20(10 suppl): S14-19. doi: 10.12968/bjen.2016.21.Sup4.S30

Fife CE, Maus EA, Carter MJ (2010) Lipoedema: a frequently misdiagnosed and misunderstood fatty deposition syndrome. Adv Skin Wounds Care 23: 81-9

Földi E, Földi M (2003) Lipedema, Chapter 9. In: Földi M, Földi E, Kubik S (eds) Textbook of Lymphology. pp395-403. Munich, Amsterdam, New York: Elsevier

Forner-Cordero I, Szolnoky G, Forner-Cordero A et al (2012) Lipedema: an overview of its clinical manifestations, diagnosis and treatment of the disproportional fatty deposition syndrome - systematic review. Clin Obes 2: 86-95. doi: 10.1111/j.1758-8111.2012.00045.x

Herbst K (2012) Rare adipose disorders (RADs) masquerading as obesity. Acta Pharmacol Sin 33(2): 155-72

Langendoen SI, Habbema L, Nijsten TEC, Neumann HAM (2009) Lipoedema: from clinical presentation to therapy. liposuction in lipoedema yields good long-term results. $\mathrm{Br} J$ Dermatol 166(1): 161-8

Smeenge J, Damstra RJ, Hendrickx AA (2014) Comparison of muscles strength in lipoedema and obesity at Nij Smellinghe Hospital, Netherlands. Presentation at ILF conference, Glasgow, May

Szél E, Kemény L, Groma G, Szolnoky G (2014) Pathophysiological dilemmas of lipoedema. Med Hypotheses 83(5): 599-60. doi: 10.1016/j.mehy.2014.08.011

Szolnoky G, Kemény L (2010) Lipoedema: from clinical presentation to therapy. Further aspects. $\mathrm{Br} J$ Dermatol 162(4): 889

Talk Lipoedema (2015) Survey of other conditions in women with lipoedema. Talk Lipoedema Spring Conference, Birmingham.

Wittlinger H, Wittlinger D, Wittlinger A, Wittlinger M (2011) Dr Vodder's Manual Lymph Drainage. A Practical Guide. Stuttgart: Thieme

Wounds UK (2015) Best Practice Statement. Compression hosiery (2nd edn). London: Wounds UK
Schmeller W, Meier-Vollrath I, Hueppe M (2012) Tumescent 